Supporting Information

\title{
Structure and mechanism of the ketosynthase- chain length factor didomain from a prototypical polyunsaturated fatty acid synthase
}

\author{
Omar Santín ${ }^{1,5}$, Kai Yuet ${ }^{2,3,4}$, Chaitan Khosla ${ }^{2,3,4 *}$ and \\ Gabriel Moncalián ${ }^{1 *}$ \\ ${ }^{1}$ Departamento de Biología Molecular, Universidad de Cantabria and Instituto de \\ Biomedicina y Biotecnología de Cantabria (IBBTEC), CSIC-Universidad de Cantabria, \\ E-39011 Santander, Spain. \\ ${ }^{2}$ Department of Chemistry, Stanford University, Stanford, CA, 94305; \\ ${ }^{3}$ Department of Chemical Engineering, Stanford University, Stanford, CA, 94305; \\ ${ }^{4}$ Stanford ChEM-H, Stanford University, Stanford, CA, 94305
}

${ }^{*}$ Correspondence: Chaitan Khosla khosla@stanford.edu; Gabriel Moncalián moncalig@unican.es

${ }^{5}$ Present address: Instituto de Investigação e Inovação em Saúde, Universidade do Porto, 4200-135 Porto, Portugal. 
Table S1. Oligonucleotides used for cloning

\begin{tabular}{|l|l|l|}
\hline $\begin{array}{l}\text { Gibson } \\
\text { assembly } \\
\text { adaptors }\end{array}$ & Forward & Reverse \\
\hline Pet29c & ctcgagcaccaccaccacc & atgtatatctccttcttaaagttaaacaaaattatttc \\
\hline Pet3a & ggatccggctgctaacaaagc & $\begin{array}{l}\text { atgtatatctccttcttaaagttaaacaaaattatttct } \\
\text { ag }\end{array}$ \\
\hline Constructions & & \\
\hline mKS-AT & $\begin{array}{l}\text { tagaaataattttgtttaactttaagaaggagatat } \\
\text { acatatggctaaaaagaacaccacatcg }\end{array}$ & $\begin{array}{l}\text { ttagcagccggatctcagtggtggtggtggtggtgct } \\
\text { cgatgcaaccgccgcgttattactgacactag }\end{array}$ \\
\hline mACP & $\begin{array}{l}\text { tagaaataattttgtttaactttaagaaggagatat } \\
\text { acatatgatcgatgtagcaactattaac }\end{array}$ & $\begin{array}{l}\text { tagcagccggatctcagtggtggtggtggtggtgctc } \\
\text { gagtgcacttgttacaggtactgttgtaggagctac }\end{array}$ \\
\hline mKS-CLF $c$ & $\begin{array}{l}\text { tagaaataattttgtttaactttaagaaggagatat } \\
\text { acatatggaaaatattgcagtagtaggtattgc }\end{array}$ & $\begin{array}{l}\text { tagcagccggatctcagtggtggtggtggtggtgctc } \\
\text { gagcgcactgttaacaatcgcgttgctaattaac }\end{array}$ \\
\hline PfaE & $\begin{array}{l}\text { caactcagcttcctttcgggctttgttagcagccgg } \\
\text { atccatgtacagcggcgtaaaagataagctcacc }\end{array}$ & $\begin{array}{l}\text { tagaaataattttgtttaactttaagaaggagatatac } \\
\text { atctatttagcgtcaggtttaaaattagtctcagg }\end{array}$ \\
\hline mKSC196A & $\begin{array}{l}\text { tcacattttgcactggatgcggctGCtgcttcatctt } \\
\text { gttatagcgttaag }\end{array}$ & $\begin{array}{l}\text { cttaacgctataacaagatgaagcaGCagccgcatc } \\
\text { cagtgcaaaatgtga }\end{array}$ \\
\hline
\end{tabular}


Table S2. Data collection and refinement statistics for mKS-CLF structurea ${ }^{a}$.

\begin{tabular}{|c|c|c|c|}
\hline Wavelength & 1.127 & $\begin{array}{l}\text { Number of non- } \\
\text { hydrogen atoms }\end{array}$ & 7335 \\
\hline Resolution range & $27.05-1.85(1.916-1.85)$ & macromolecules & 6928 \\
\hline Space group & $P 2_{1} 2_{1} 2_{1}$ & ligands & 1 \\
\hline Unit cell & $\begin{array}{l}a=78.24 b=90.83 \\
c=132.42 \\
\alpha=\beta=\gamma=90\end{array}$ & solvent & 669 \\
\hline Total reflections & 2195157 (218608) & Protein residues & 931 \\
\hline Unique reflections & $80533(11547)$ & RMS(bonds) & 0.016 \\
\hline Multiplicity & $4.2(4.1)$ & RMS(angles) & 1.90 \\
\hline Completeness (\%) & $99.3(99.2)$ & $\begin{array}{l}\text { Ramachandran } \\
\text { favored (\%) }\end{array}$ & 98.37 \\
\hline Mean I/sigma(I) & $37.83(2.62)$ & $\begin{array}{l}\text { Ramachandran } \\
\text { allowed (\%) }\end{array}$ & 1.41 \\
\hline Wilson B-factor & 20.08 & \begin{tabular}{|l|} 
Ramachandran \\
outliers (\%)
\end{tabular} & 0.22 \\
\hline R-merge & $0.069(0.358)$ & Rotamer outliers (\%) & 1.61 \\
\hline R-meas & $0.079(0.412)$ & Clashscore & 2.81 \\
\hline $\mathrm{CC} 1 / 2$ & $0.863(0.559)$ & Average B-factor & 25.11 \\
\hline $\mathrm{CC}^{*}$ & $0.941(0.863)$ & macromolecules & 22.30 \\
\hline $\begin{array}{l}\text { Reflections used in } \\
\text { refinement }\end{array}$ & 73870 (7195) & ligands & 28.70 \\
\hline $\begin{array}{l}\text { Reflections used } \\
\text { for R-free }\end{array}$ & $3705(356)$ & solvent & 31.38 \\
\hline R-work & $0.1574(0.2138)$ & & \\
\hline R-free & $0.1813(0.2460)$ & & \\
\hline CC(work) & $0.812(0.738)$ & & \\
\hline CC(free) & $0.811(0.717)$ & & \\
\hline
\end{tabular}

a Statistics for the highest-resolution shell are shown in parentheses. 


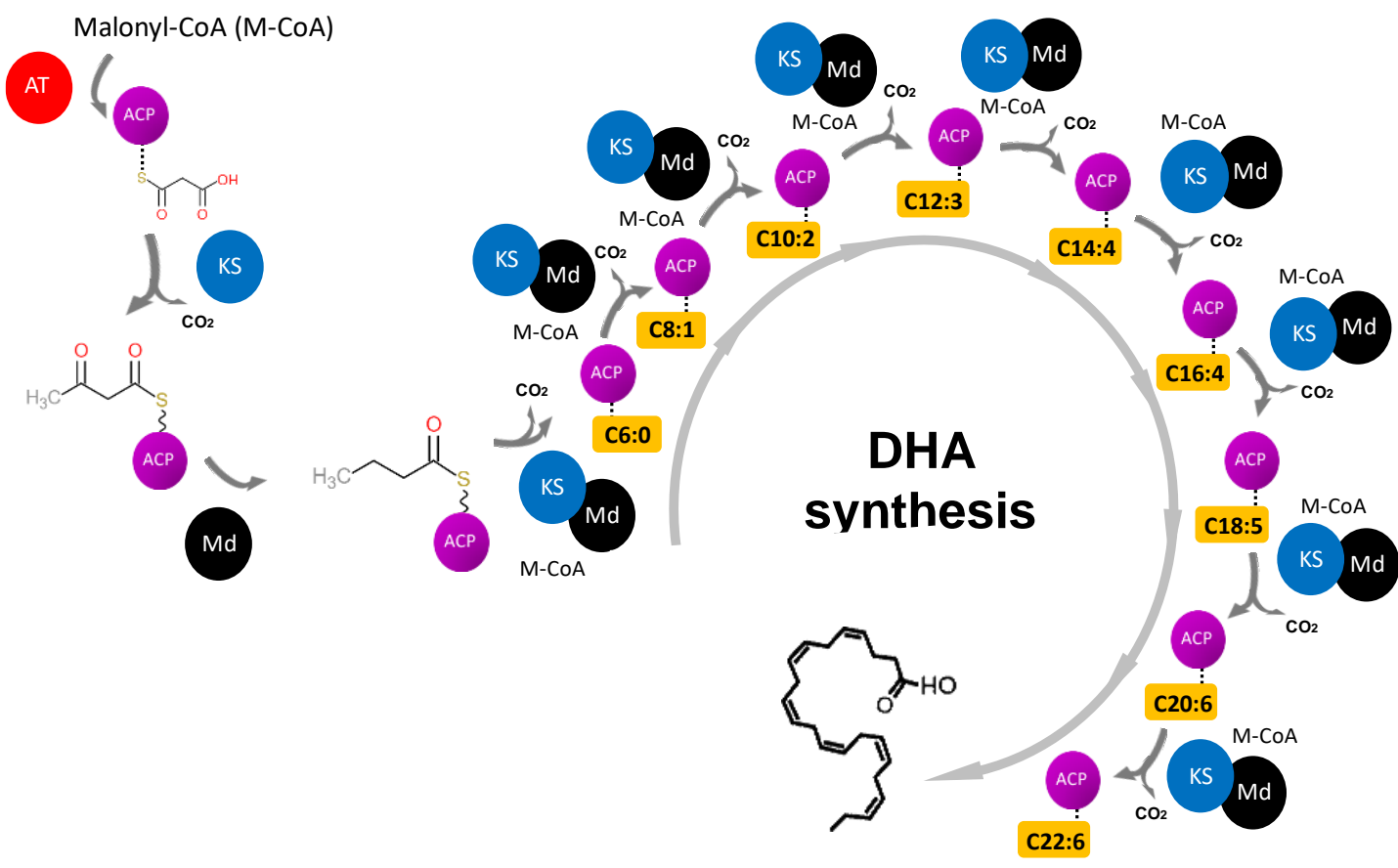

Figure S1. DHA biosynthesis: The chain length and the degree of unsaturation of each intermediate is indicated in the yellow rectangles. Condensation reactions by ketosynthase domains are represented by blue circles. Post-condensation modifications (reductions and dehydrations) produced by KR, DH and/or ER domains are represented by black circles labeled "Md". 

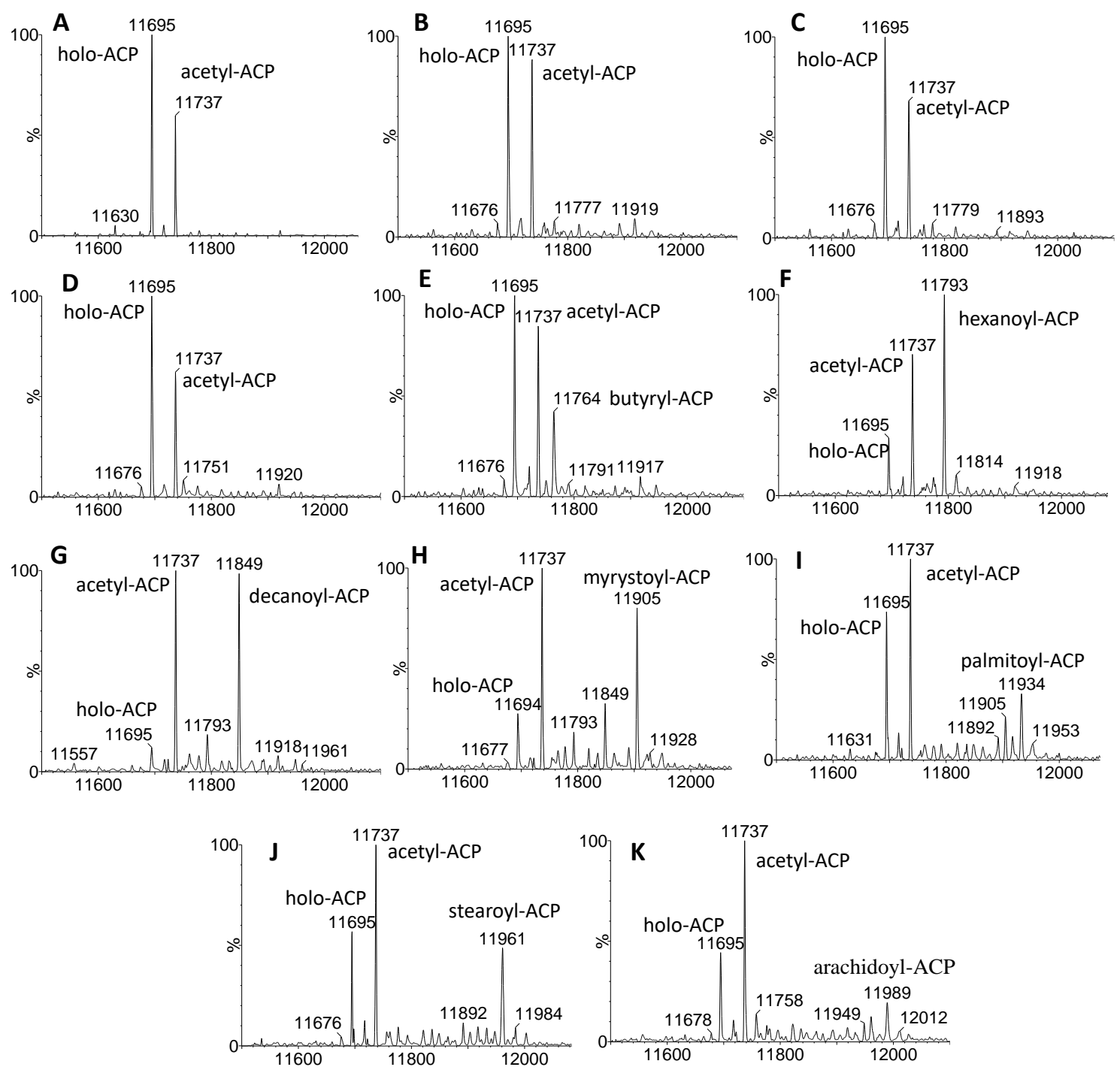

Figure S2. mKS-CLF promoted back-transfer of acyl chains from acyl-CoA species to $\mathrm{mACP}$. MS of reactions containing holo-mACP, mKS-CLF, and various acyl-CoA substrates, as described in Experimental Procedures. (A) No substrate (some acetyl$\mathrm{ACP}$ is observed, presumably due to the relative abundance of acetyl-CoA in E. coli under conditions where $\mathrm{mACP}$ and $\mathrm{mPfaE}$ are co-expressed); (B) acetyl-CoA $\left(\mathrm{C}_{2}\right) ;(\mathrm{C})$ malonyl-CoA $\left(\mathrm{C}_{3-\mathrm{COOH}}\right)$; (D) propionyl-CoA $\left(\mathrm{C}_{3}\right)$; (E) butyryl-CoA $\left(\mathrm{C}_{4}\right)$; $(\mathrm{F})$ hexanoylCoA $\left(\mathrm{C}_{6}\right)$; (G) decanoyl-CoA $\left(\mathrm{C}_{10}\right)$; (H) myristoyl-CoA $\left(\mathrm{C}_{14}\right)$; (I) palmitoyl-CoA $\left(\mathrm{C}_{16}\right)$; $(\mathrm{J})$ stearoyl-CoA $\left(\mathrm{C}_{18}\right)$; and $(\mathrm{K})$ arachidoyl-CoA $\left(\mathrm{C}_{20}\right)$. 

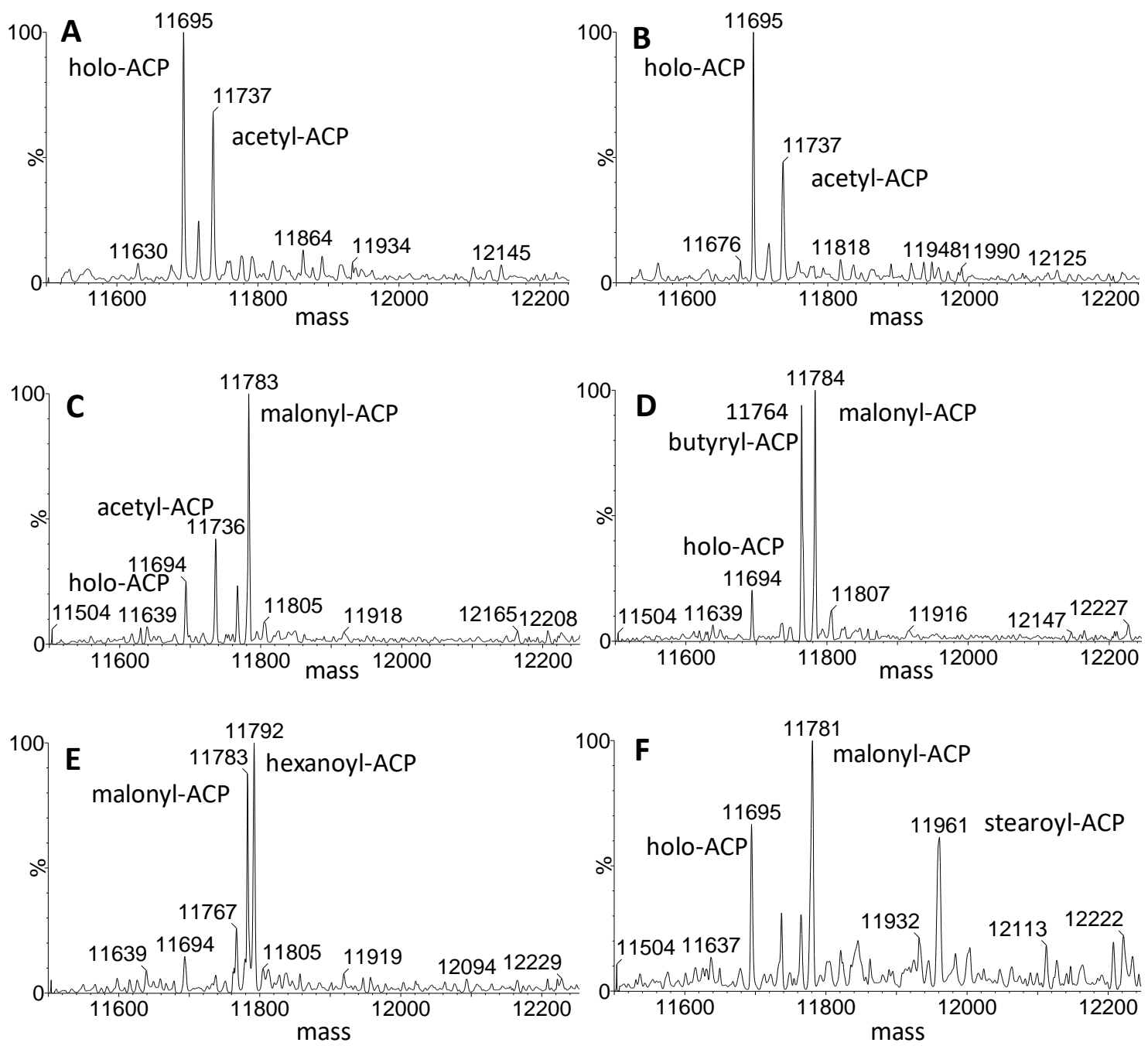

Figure S3. Mass spectrometric analysis of reactions containing mKS-CLF C196A and various substrates. (A) holo-mACP and hexanoyl-CoA; (B) holo-mACP and stearoyl$\mathrm{CoA}$; (C) $\left[2-{ }^{13} \mathrm{C}\right]$ malonyl-ACP and acetyl-ACP; (D) $\left[2-{ }^{13} \mathrm{C}\right]$ malonyl-ACP and butyryl$\mathrm{ACP}$; (E) $\left[2-{ }^{13} \mathrm{C}\right]$ malonyl-ACP and stearoyl-ACP; (F) mKS-AT with $\left[2-{ }^{13} \mathrm{C}\right]$ malonylACP and stearoyl-ACP. 


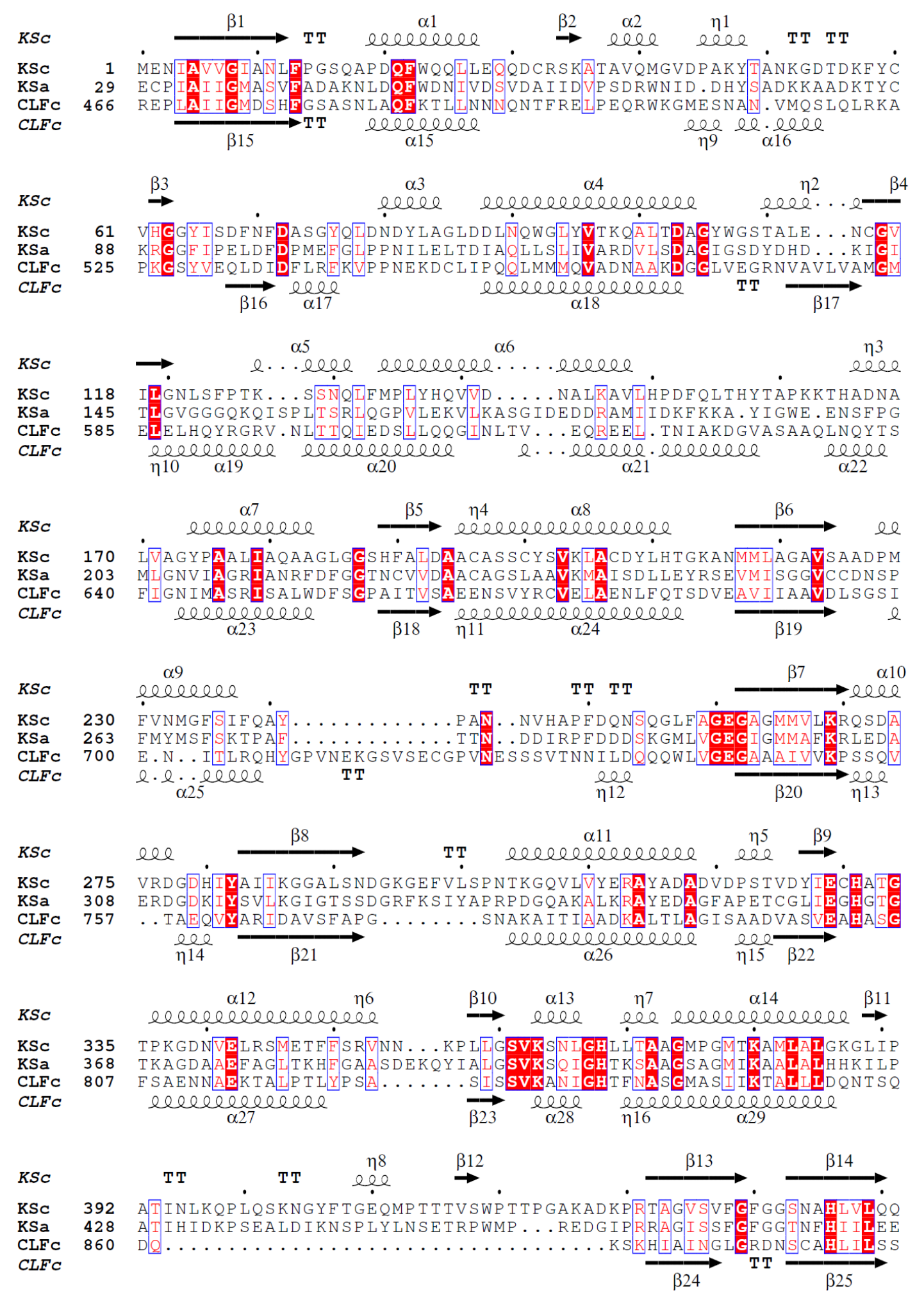

Figure S4. Alignment of the $\mathrm{KS}_{\mathrm{C}}$ and CLF domains of mKS-CLF with the KS domain of $\mathrm{mPfaA}\left(\mathrm{KS}_{\mathrm{A}}\right)$. Alignment was prepared using ESPRIPT(Gouet et al., 1999). Identical residues are shown in white and conserved residues in red. Secondary structure elements of $\mathrm{KS}_{\mathrm{C}}$ and $\mathrm{CLF}$ according to the $\mathrm{mKS}-\mathrm{CLF}$ structure are shown. 


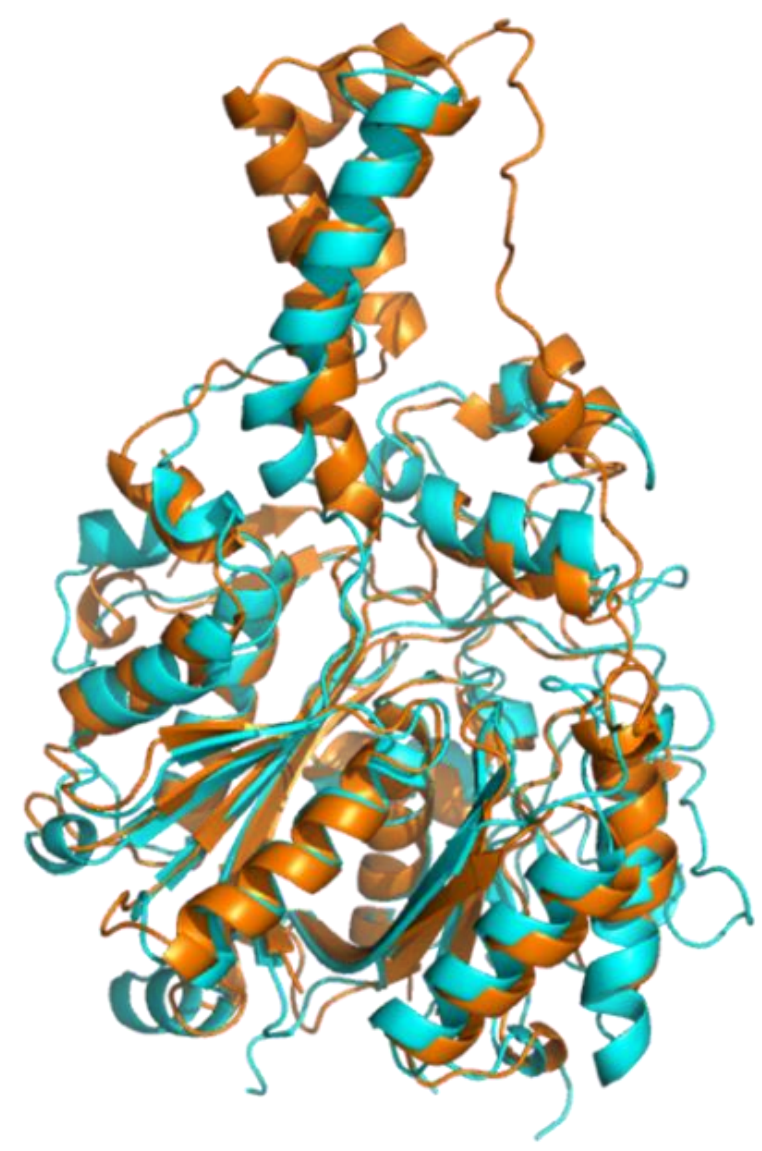

Figure S5. Superposition of the backbones of the $\mathrm{KS}_{\mathrm{C}}$ (cyan) and the CLF (orange) domains. 


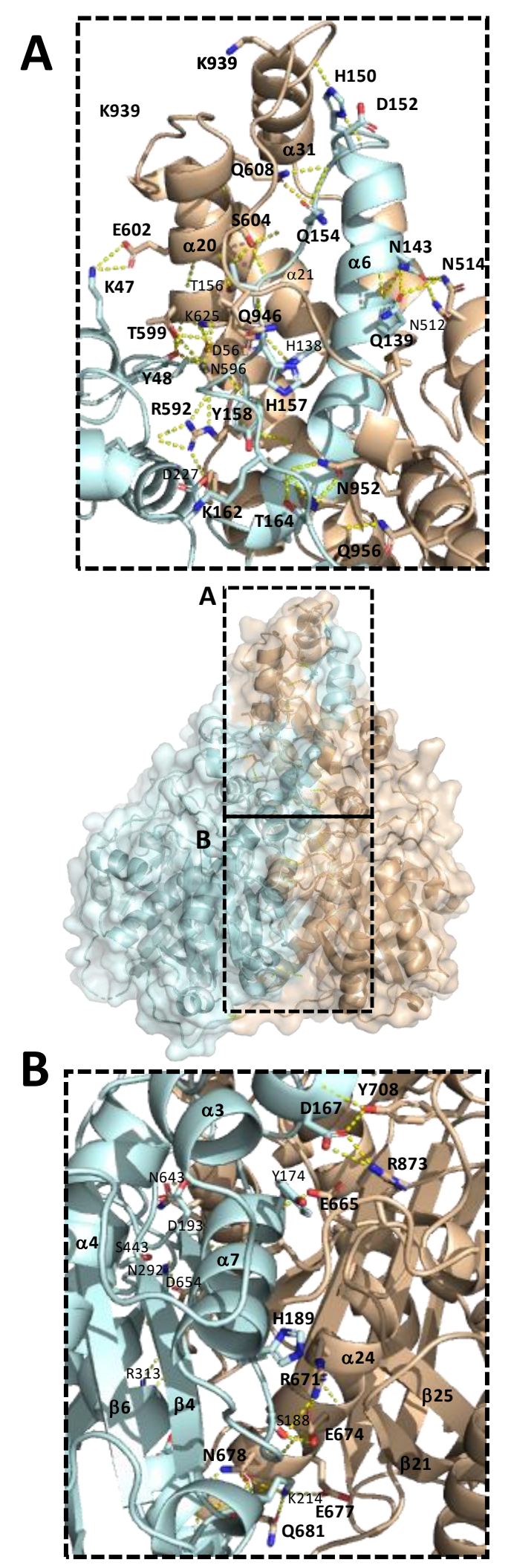

Figure S6. Residues involved in interdomain association in mKS-CLF in the upper (A), and lower (B) regions. Hydrogen bonds are shown as yellow dashed lines. KS domain is shown in cyan and CLF domain in wheat. Secondary structure elements are numbered as in Fig. 3. 


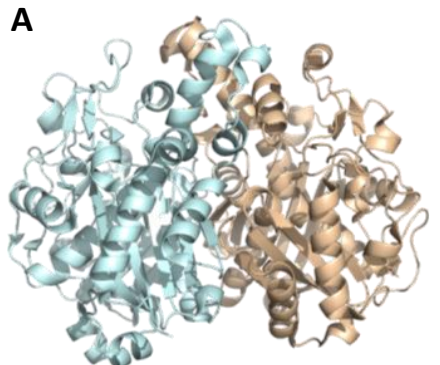

Act KS-CLF

C

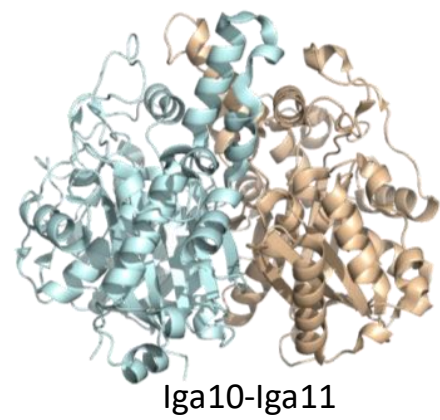

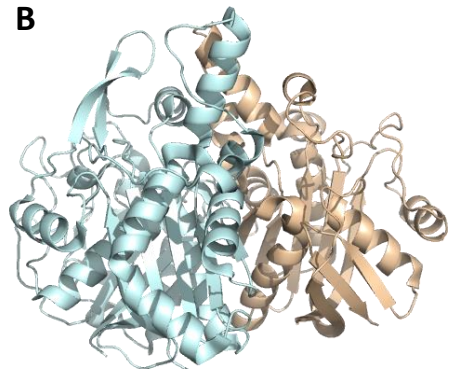

ApeC-ApeO

D

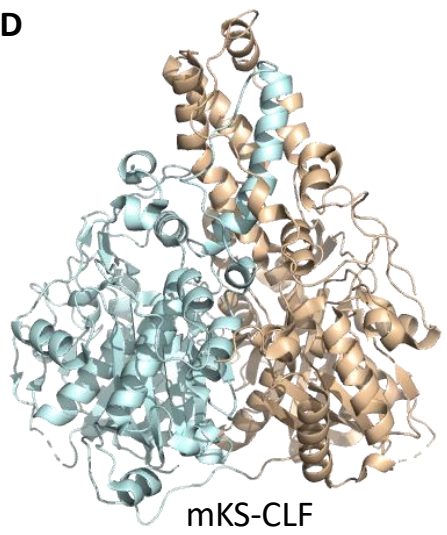

E

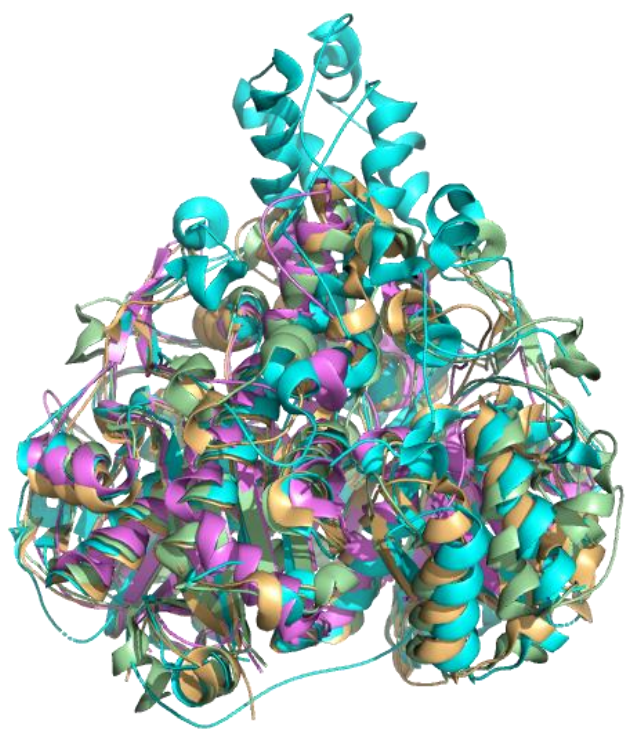

Figure S7. Comparison of the mKS-CLF didomain and other heterodimeric KS-CLF proteins. Overall structures of actinorhodin act KS-CLF (PDB ID: 1TQY) (A), ApeOApeC (PDB ID: 6QSP) (B), Iga11-Iga12 (PDB ID: 6KXF) (C) and mKS-CLF (D). KS domains are shown in wheat color and CLF domains in pale cyan. (E) Superimposition of the backbone of mKS-CLF (cyan) with the backbone of actinorhodin KS-CLF (green, RMSD=2.43), ApeO-ApeC (violet, RMSD=2.37) and Iga11-Iga12 (orange, $\mathrm{RMSD}=2.42$ ). 

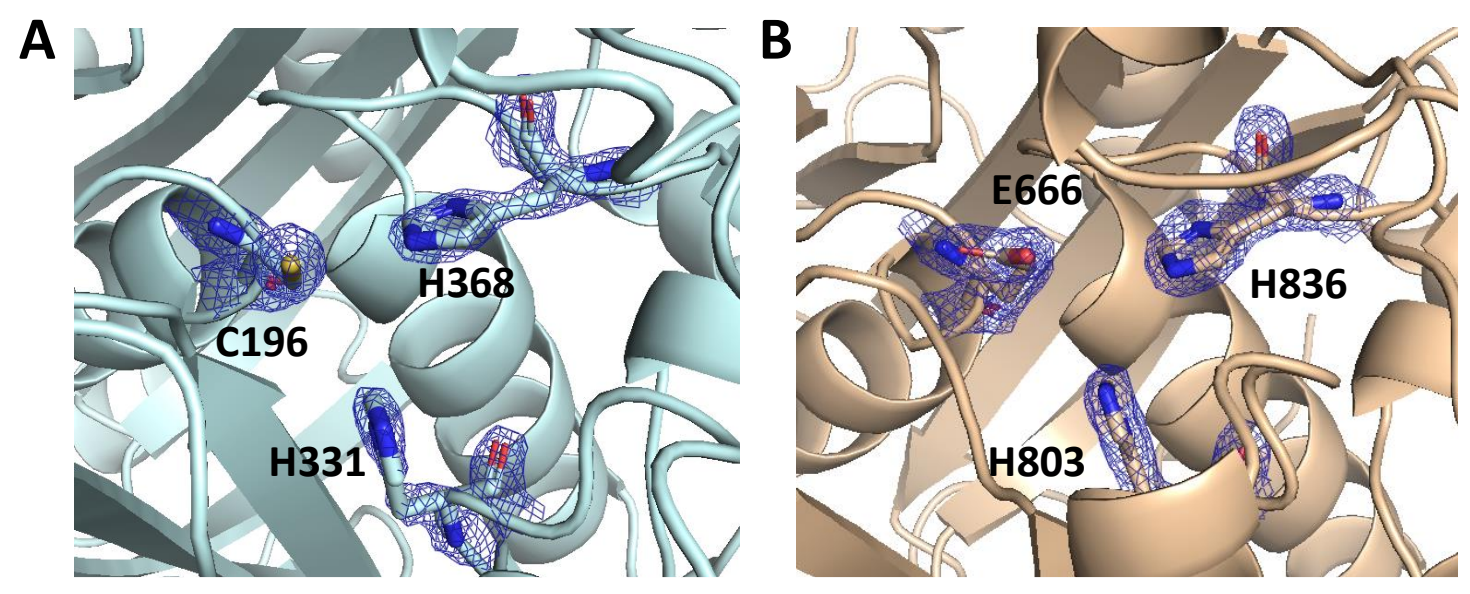

Figure S8. The active site of mKS-CLF. (A) The Cys-His-His catalytic triad of the $\mathrm{KS}_{\mathrm{C}}$ domain, and (B) the homologous, non-functional, Glu-His-His residues in the corresponding pocket of the CLF domain. The $2 \mathrm{Fo}-\mathrm{Fc}$ map is shown for the highlighted residues.

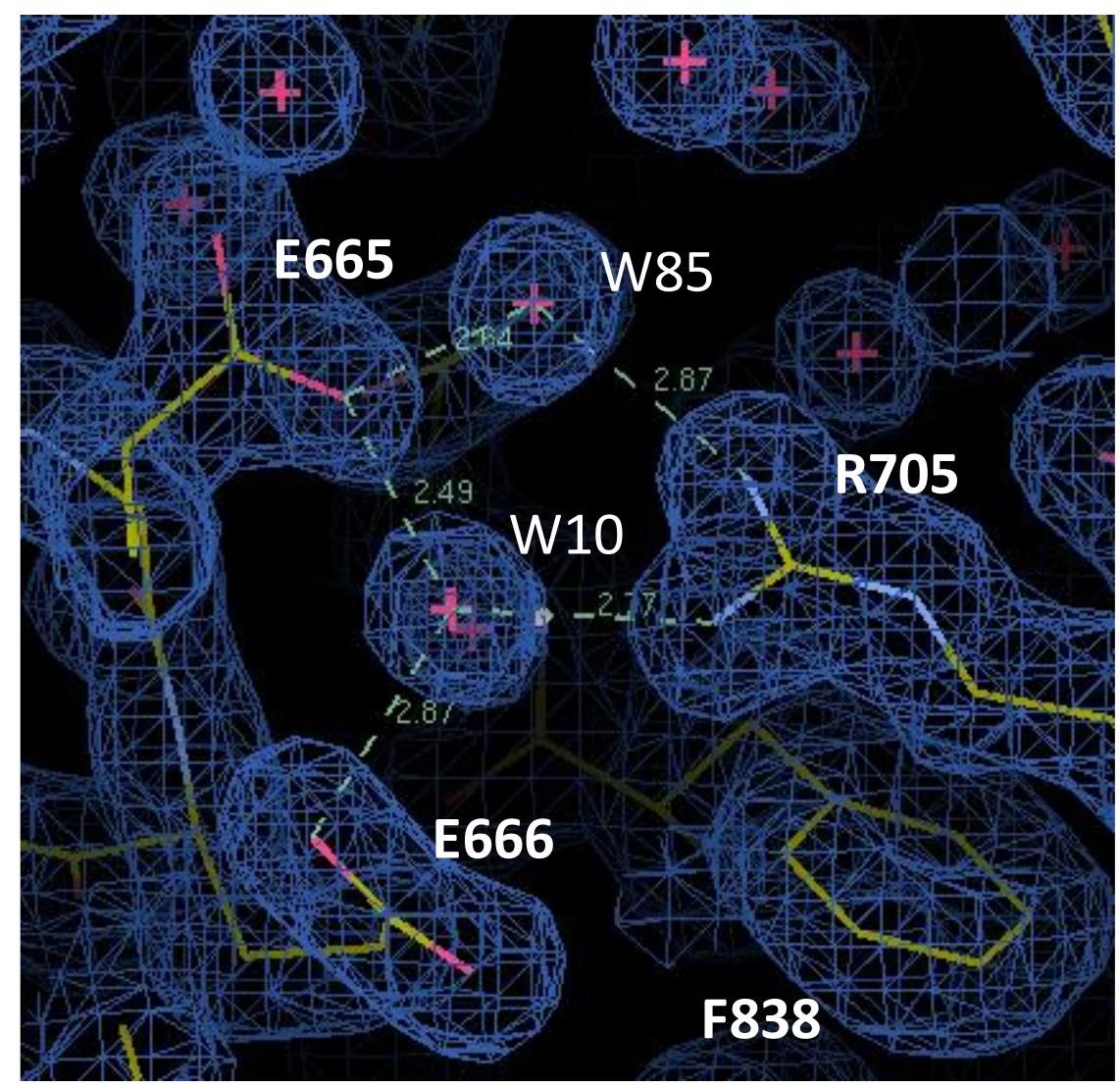

Figure S9. Interaction between E665, E666 and R705 within KS-CLF structure. 2Fo-Fc map is shown. 


\section{References}

Gouet, P., Courcelle, E., Stuart, D.I., and Métoz, F. (1999). ESPript: analysis of multiple sequence alignments in PostScript. Bioinformatics 15, 305-308. 